\title{
Analisis Jaringan Komunikasi pada Level Aktor dalam Jaringan Komite Pengusaha Alas Kaki Kota Mojokerto (Kompak)
}

\author{
Dhelittya Finaliyani Putri', Anang Sujoko², dan Antoni*3 \\ ${ }_{1,2,3}$ Universitas Brawijaya \\ E-mail: dhelittya@gmail.com, anangsujoko@gmail.com,ant_ui@yahoo.com* \\ *corresponding author
}

Key words:

Network communication

Actor

Centrality actor

Kata kunci:

Jaringan komunikasi

Aktor

Sentralitas aktor

\begin{abstract}
Mojokerto City has a creative industry that contains footwear since 1994 until now. This industry has been supported by the government with the establishment of an organization called Mojokerto City Footwear Employers Committee (KOMPAK). Through this service the craftsmen get information about what is needed, capital, and related to job training from local government. Based on the flow of information exchange, formed communications networks that form a special structure for the purpose of business development. This study aims to see the communication network formed from shoe footwear craftsmen who are incorporated in the organization in order to know the level of a healthy actor based on the level of centrality. To know the position of the perpetrator based on the level of centrality, the program needed UCINET 6 version 6.658 . Through the UCINET program it can find out who is the most dominant and most profitable in its network. The results showed the communication network between craftsmen who centralized the existing meaning of the role of individuals as fellow craftsmen who are members of the KOMPAK organization.
\end{abstract}

\begin{abstract}
ABSTRAK
Kota Mojokerto memiliki industri kreatif yang berupa alas kaki sejak tahun 1994 sampai dengan sekarang. Industri ini sudah didukung oleh pemerintah dengan upaya pembentukan organisasi yang bernama Komite Pengusaha Alas Kaki Kota Mojokerto (KOMPAK). Melalui organisasi ini para pengrajin mendapatkan informasi mengenai kebutuhan pemasaran, permodalan, dan terkait pelatihan kerja dari pemerintah daerah. Berdasarkan arus pertukaran informasi sehingga terbentuklah jaringan komunikasi yang membentuk struktur tertentu untuk kegunaan pengembangan usaha. Penelitian ini bertujuan melihat jaringan komunikasi yang terbentuk dari para pengrajin alas kaki sepatu yang tergabung dalam organisasi agar dapat mengetahui level aktor yang berpengaruh berdasarkan level sentralitas. Untuk mengetahui posisi aktor berdasarkan level sentralitas, dibutuhkan program UCINET 6 versi 6.658. Melalui program UCINET maka dapat terlihat aktor mana yang paling dominan dan yang paling berpengaruh dalam jaringannya. Hasil penelitian menunjukkan jaringan komunikasi antar pengrajin yang memusat memberi arti bahwa ada peran dominan individu diantara sesama pengrajin yang tergabung dalam organisasi KOMPAK.
\end{abstract}

Copyright (C) 2018 Channel Jurnal Komunikasi. All right reserved. 


\section{PENDAHULUAN}

Kota Mojokerto merupakan kota terkecil di Provinsi Jawa Timur yang hanya memiliki luas wilayah 16,45 $\mathrm{km}^{2}$. Kota Mojokerto memiliki dua kecamatan yaitu Kecamatan Magersari dan Prajurit Kulon. Kota Mojokerto juga memiliki industri kreatif yang berupa alas kaki berbahan kulit sejak tahun 1994 sampai dengan sekarang. Pada tahun 2012 Indutri Alas Kaki ditetapkan sebagai core industry atau Kompetensi Inti Industri Daerah (KIID), hal ini sesuai dengan kesepakatan bersama antara Dinas Perindustrian dan Perdagangan Provinsi Jawa Timur dengan Dinas Koperasi, Perindustrian dan Perdagangan Kota Mojokerto terhadap pola pembinaan Industri Alas Kaki. Penetapan Industri Alas Kaki Kota Mojokerto sebagai KIID juga berdasar kajian tentang Kompetensi Inti Industri daerah yang dilakukan pada Tahun 2012. Beberapa wilayah di Mojokerto memiliki industri alas kaki rumahan, Kecamatan Miji mempunyai 45 industri alas kaki; Surodinawan memiliki 70 industri alas kaki; dan Prajurit Kulon memiliki 82 industri alas kaki (Ardhala, Eko, Santoso, Ir, \& Sulistiyarso, 2016).

Pemerintah memperkuat kerjasama antara Komite Pengusaha Alas Kaki atau yang biasa dikenal dengan KOMPAK sebagai upaya peningkatan kualitas dari produk, kemasan, ekspansi pasar dan saluran penjualannya. Organisasi ini dibangun atas program pemerintah yang lahir pada tahun 2008 sebagai wadah penyaluran informasi para pengrajin yang sudah menjadi anggota organisasi. Keberadaan KOMPAK ini juga merupakan satu-satunya organisasi yang dilegalkan oleh pemerintah sebagai pusat bertemunya para pengrajin industri alas kaki Kota Mojokerto. Organisasi ini juga berkontribusi untuk membantu para pengrajin alas kaki Kota Mojokerto untuk memasarkan produk dan mendapatkan bantuan dari pemerintah seperti proses permodalan maupun pelatihan kerja. Adanya organisasi ini juga dapat mempermudah kordinasi antar pengrajin alas kaki dan pemerintah daerah. Keberadaan organisasi KOMPAK yang juga memiliki struktur organisasi seperti organisasi lainnya, terdiri dari ketua, bendahara, sekretaris, seksi bidang pemasaran, seksi bidang produksi, seksi bidang bahan baku, dan anggota mempunyai keterkaitan hubungan aktor satu dengan aktor lainnya dalam organisasi. Dalam struktur organisasi di KOMPAK ini memiliki aktor-aktor yang mempunyai peranan masing-masing untuk berkontribusi membangun organisasi dan mempertahankan hingga saat ini. Peranan aktor tersebut yang menurut Rogers dan Kincaid, (1981) sama seperti tujuan penelitian jaringan komunikasi untuk memahami fenomena secara umum mengenai interaksi manusia dalam sistem sosial dan mengidentifikasi struktur komunikasi yang menyusunnya. Peran masing-masing aktor dalam jaringan komunikasi berbeda-beda, konsep pemuka pendapat (opinion leader) dan penjaga gerbang (gatekeeper) dikenal dalam mempercepat penyebaran suatu gagasan atau teknologi baru kepada masyarakat (Velante dan Davis, 1999).

Studi ini berangkat dari pemikiran bahwa sebuah hubungan sehari-hari atau hubungan kedekatan yang dilandasi dengan kesamaan tertentu membentuk sebuah jaringan (Monge \& Contractor, 2003). Pemahaman mengenai jaringan (networks) sendiri merupakan susunan sosial yang diciptakan oleh komunikasi antar individu dan kelompok (Monge \& Contractor, 2003; Galaskiewicz, 2007; Scott, 1988; Crossley, Prell, \& Scott, 2009; Borgatti \& Foster, 2003). Sebuah jaringan merupakan hasil sebuah proses interaksi dan hubungan antar individu yang memiliki kepentingan bersama. Proses interaksi dan komunikasi tersebut yang mampu dikaji melalui fenomena komunikasi. Individu-individu yang saling berkomunikasi dan saling terhubung ke dalam kelompok-kelompok yang selanjutnya saling terhubung ke dalam sebuah jaringan (Galaskiewicz \& Wasserman, 1993; Monge \& Contractor, 2003).

Jaringan komunikasi yang terbentuk dari para pengrajin alas kaki sepatu ini dalam berkomunikasi dilihat sebagai upaya pengrajin mendapatkan bantuan, penyaluran informasi, dan perkembangan industri yang didapatkan dari pemerintah daerah. Jaringan komunikasi ini penting untuk dianalisis karena dalam penerapan usaha alas kaki terdapat kondisi yang menggambarkan relasi aktor satu dengan aktor lain dalam jaringan. Aspek penting lain dari studi tentang jaringan adalah bagaimana keteraturan struktural mempengaruhi perilaku para pelaku. Jelas bahwa ide-ide ini yang berasal studi jaringan ini dapat menawarkan nilai tambah bagi penyelidikan dalam banyak disiplin ilmu (Otte \& Rousseau, 2002).

Substansi analisis jaringan adalah mengenai hubungan (relation) yakni menyangkut hakikat koneksi komunikasi di antara individu, kelompok, dan organisasi. Konsep hubungan (relation) memiliki dimensi seperti kekuatan (strength), kesetaraan (symmetry), memerlukan objek (transitivity), saling berhubungan (reciprocity), dan banyak struktur (multiplexity) (Monge \& Contractor, 2003). Gagasan struktural dasar dari teori jaringan adalah keterkaitan (connectedness) atau sebuah gagasan dengan adanya pola komunikasi yang cukup stabil antar individu. Individu-individu yang saling berkomunikasi saling terhubung ke dalam kelompok-kelompok yang selanjutnya saling terhubung ke dalam keseluruhan jaringan. Menurut Rogers dan Kincaid, (1981) tujuan penelitian jaringan komunikasi adalah untuk memahami fenomena secara umum mengenai interaksi manusia dalam sistem sosial dan mengidentifikasi struktur komunikasi yang menyusunnya. Peran masing-masing aktor dalam jaringan komunikasi berbeda-beda, konsep pemuka pendapat (opinion leader) dan penjaga gerbang (gatekeeper) dikenal dalam mempercepat penyebaran suatu gagasan atau teknologi baru kepada masyarakat (Velante dan Davis, 1999).

Dalam penelitian ini akan dipaparkan beberapa kajian mengenai studi jaringan yang dilihat sebagai proses interaksi, hubungan, dan komunikasi dari berbagai disiplin ilmu. Berapa penelitian yang sudah dilakukan walaupun bukan dari bidang keilmuan komunikasi dan bersifat multidisipliner, namun jika diamati secara isi merupakan sebuah proses komunikasi, seperti interaksi antar individu dan hubungan yang terjadi di dalam jaringan. 
Pertama, penelitian yang dilakukan oleh Badi, Wang \& Pryke (2016) yang meneliti tentang jaringan bisnis Guanxi pada usaha kecil dan menengah di Cina melihat keterikatan struktural dan karakteristik dalam jaringan stakeholdernya. Penelitian Badi,S.,et al (2016) melihat sebuah jaringan bisnis dalam hubungan pemasaran yang dilihat dari karakteristik masyarakat Cina dalam berbisnis dengan keterkaitan jaringan bisnis di Guanxi. Karakteristik masyarakat Cina yang digambarkan dalam penelitian ini adalah lebih mengutamakan keluarga dan budaya kepercayaan yang rendah terhadap orang asing, dengan pemahaman bahwa keluarga, teman, kerabat terdekat adalah suatu hubungan kedekatan yang sudah terbentuk sejak lama, dan memilki kepercayaan yang tinggi untuk selalu diutamakan, termasuk juga terkait dengan hubungan pemasaran dalam bisnis. Hubungan kedekatan ini yang membuat penelitian Badi,S.,et al (2016) mampu membuktikan sebuah jaringan berkorelasi dengan hubungan pemasaran dalam bisnis.

Penelitian selanjutnya adalah Pinho (2015) yang lebih menyoroti kepada penggunaan metode jaringan untuk memahami beberapa hubungan yang komplek terkait dengan proses internasionalisasi. Penawaran metode jaringan dipakai dalam penelitian ini karena melihat masih sedikit perusahaan yang menggunakan strategi internasionalisasi dengan menggabungkan metode Social Network Analysis. Dalam pengembangan strategi internasionalisasi sendiri membutuhkan kerja sama dan komitmen antara aktor dan organisasi khususnya untuk perusahaan kecil atau menengah (SME) yang masih bergantung pada sumber daya dan pengolahan informasi dari orang lain (Pinho \& Pinheiro, 2015). Ketergantungan sumber daya ini ditunjukkan dengan jenis dan sifat hubungannya, perusahaan dapat lebih baik mengakses sumber daya yang berharga di awal tahapan, di pasar domestik, dengan menggunakan sumber daya (biasanya koneksi) untuk secara bertahap meningkatkan keterlibatannya di pasar internasional. Proses interaksi ini yang menunjukkan jaringan dalam Small Medium Enterprise menentukan kesuksesan dari sebuah organisasi.

Penelitian Antoniadis \& Charmantzi (2016) juga melihat sebuah jaringan yang dikaitkan dengan modal sosial dalam pemasaran. Penggunaan analisis jaringan sosial dalam pemasaran akan menguntungkan pemasar untuk membentuk komunikasi dan strategi branding dalam modal sosial yang dilakukan melalui internet. Strategi branding yang dilakukan di internet dengan cara membuatan konten yang menarik agar pengguna menyukai dan ikut berkomentar dengan tujuan meningkatkan keterlibatan pengguna di media sosial, seperti Facebook, twitter, youtube, dsb (Antoniadis \& Charmantzi, 2016). Dalam tulisan ini, karakteristik utama dari definisi modal sosial dan analisis jaringan sosial (SNA) dilihat sebagai pentingnya modal sosial untuk pemasaran dan branding di situs jejaring sosial.

Ketiga penelitian yang sudah dipaparkan di atas menunjukkan bahwa sebuah interaksi dan hubungan-hubungan di dalam organisasi dapat membentuk sebuah jaringan. Penelitian-penelitian tersebut memang lebih menyoroti kepada hubungan pemasaran dalam Small Medium Enterprise di kajian luar negeri. Namun, kajian studi jaringan dalam Usaha Kecil dan Menengah di Indonesia sendiri juga sudah dikaji oleh beberapa peneliti.

Rudy Latuperissa (2014) adalah salah satu peneliti yang mengkaji pemetaan jaringan UKM di kluster Borobudur Jawa Tengah untuk memperkuat platform pengembangan ekonomi lokal. Penelitian ini berangkat dari pemikiran bahwa UKM memiliki peran yang penting untuk meningkatkan kontribusi kemakmuran rakyat. Pemerintah juga ikut serta dalam memberdayakan UKM dengan cara membentuk forum untuk para pemangku kepentingan agar dapat berkomunikasi dalam mengembangkan bisnis mereka. Jaringan dilihat sebagai salah satu keberhasilan dalam organisasi atau sebuah forum (Latuperissa, 2014).

Studi ini mencoba memetakan jaringan UKM di kluster Borobudur untuk mengetahui bagaimana mereka membangun relasinya. Cara mengetahui bagaimana aktor-aktor tersebut membangun sebuah relasi dengan membentuk saluran sentral untuk bertukar informasi yang bersifat audiovisual menggunakan media tatap muka (lokakarya, rapat, dan seminar). Penelitian ini menghasilkan strategi-strategi untuk pengembangan ekonomi lokal setelah berhasil memetakan jaringan yang terbentuk di UKM kluster Borobudur (Latuperissa, 2014).

Berdasarkan pengamatan terhadap studi mengenai jaringan dalam small medium enterprise di atas, ada beberapa hal dapat disampaikan. Pertama, studi jaringan ini telah dilakukan di luar negeri dan Indonesia menunjukkan topik yang beraneka ragam. Kedua, studi jaringan merupakan studi yang dilakukan dengan berbagai pendekatan disiplin ilmu pengetahuan dengan mengkaji berbagai macam aspek. Ketiga, pemaparan kajian studi jaringan dalam hubungan pemasaran di Small Medium Enterprise yang dilihat sebagai interaksi dan hubungan dan dapat dilihat sebagai fenomena komunikasi.

Dengan menggunakan analisis jaringan komunikasi, maka akan membantu melihat struktur organisasi dalam small medium enterprise Kota Mojokerto dengan melihat peran/posisi masing-masing aktor dalam pertukaran informasi tentang usaha alas kaki ini. Untuk meneliti peran/posisi masing-masing aktor diukur dengan sentralitas (centrality), yaitu melihat siapa aktor yang paling menonjol dan paling menentukan dalam keseluruhan jaringan (complete network). Ada empat ukuran sentralitas yang digunakan, antara lain 1) Sentralitas tingkatan (degree centrality), 2) Sentralitas kedekatan (closeness centrality), 3) Sentralitas keperantaraan (betweeness centrality), dan 4) Sentralitas Eigenvektor (Eigenvector Centrality). 


\section{METODE PENELITIAN}

Penelitian ini menggunakan metode analisis jaringan komunikasi untuk mengidentifikasi struktur komunikasi dalam suatu sistem, dimana data hubungan mengenai arus komunikasi dianalisis dengan menggunakan beberapa tipe hubungan interaksi sebagai unit-unit analisis. Pendekatan Post-Positivistik dipakai dalam penelitian ini karena dalam studi analisis jaringan komunikasi memerlukan beberapa pengumpulan data kuantitatif dan kualitatif (Williams \& Shepherd, 2017). Jika dalam pendekatan Positivistik bertujuan untuk dapat menemukan hukum secara general, sehingga manusia dapat melakukan prediksi dan kontrol terhadap sebuah kejadian atau fenomena, maka pendekatan Post-Positivistik membantu untuk menjelaskan realisme kritis yang nyata, namun tidak bisa dipahami secara sempurna dan probabilistik (Creswell, 2012).

Dalam penelitian jaringan komunikasi terdapat beberapa gabungan pengumpulan data kuantitatif dan kualitatifyang dijelaskan secara deskriptif. Data kuantitatif yang dimaksud dalam penelitian ini adalah data relasional, yang bersumber dari nama-nama yang telah dipilih oleh informan dalam kuesioner. Kemudian, nama-nama tersebut di input kedalam suatu program (misalnya Microsoft Excel) terlebih dahulu, sebelum nantinya akan diinput ke dalam program pengolahan data analisis jaringan sosial, UCINET. Dengan bantuan perangkat lunak UCINET 6, program yang dikembangkan oleh Borgatti dan rekan-rekannya untuk ilmu sosial (Borgatti \& Foster, 2003). UCINET 6 dipilih dari nomor alat yang tersedia karena relatif mudah digunakan dan jangkauan yang luas untuk pemilihan analisis (Huisman \& Van Duijn, 2005). Setelah entri data selesai, kemudian membuat gambar sosiometri dan sosiogram dengan menggunakan software NetDraw, software ini satu paket dengan UCINET. Setelah gambar sosiometri dan sosiogram tersaji, kemudian data tersebut diolah menggunakan analisis data pada level sentralitas aktor. Selanjutnya, pengumpulan data kualitatif dilakukan dengan hasil wawancara yang dilakukan oleh peneliti, data tersebut bukan merupakan isi pesan yang disampaikan dari satu aktor ke aktor yang lain dalam jaringan. Data yang diperoleh dalam penelitian ini baik didapat dari wawancara terstruktur dan wawancara tidak terstruktur akan digunakan untuk membahas lebih detail mengenai bagaimana sebuah hubungan terbentuk antar pengrajin dalam organisasi KOMPAK.

Fokus penelitian adalah untuk mendeskripsikan jaringan komunikasi yang ditekankan pada analisa jaringan utuh (complete networks) pada level aktor. Jaringan komunikasi yang dipilih sebagai indikator adalah sentralitas tingkatan, sentralitas kedekatan, sentralitas keperantaraan dan sentralitas eigenvektor. Populasi dalam penelitian ini adalah seluruh pengrajin alas kaki yang tergabung dalam organisasi KOMPAK yang berjumlah 60 orang. Metode penentuan sampel (Design Sampling) dilakukan dengan cara "Representative Sample of Intact System" dengan hanya mengambil responden sebanyak 15 orang pengrajin yang tergabung di organisasi KOMPAK.

\section{HASIL DAN ANALISIS}

\section{a. Struktur Organisasi vs Jaringan Komunikasi}

Komite Pengusaha Alas Kaki Kota Mojokerto (KOMPAK) tentunya memiliki struktur organisasi sendiri, struktur organisasi ini berbeda dengan jaringan komunikasi yang terbentuk antara para pengrajin sepatu yang tergabung dalam organisasi KOMPAK. Berikut ini merupakan pemaparan mengenai struktur organisasi yang terbentuk di KOMPAK dan dikaitkan dengan jaringan komunikasi antar aktor untuk melihat sentralitas.

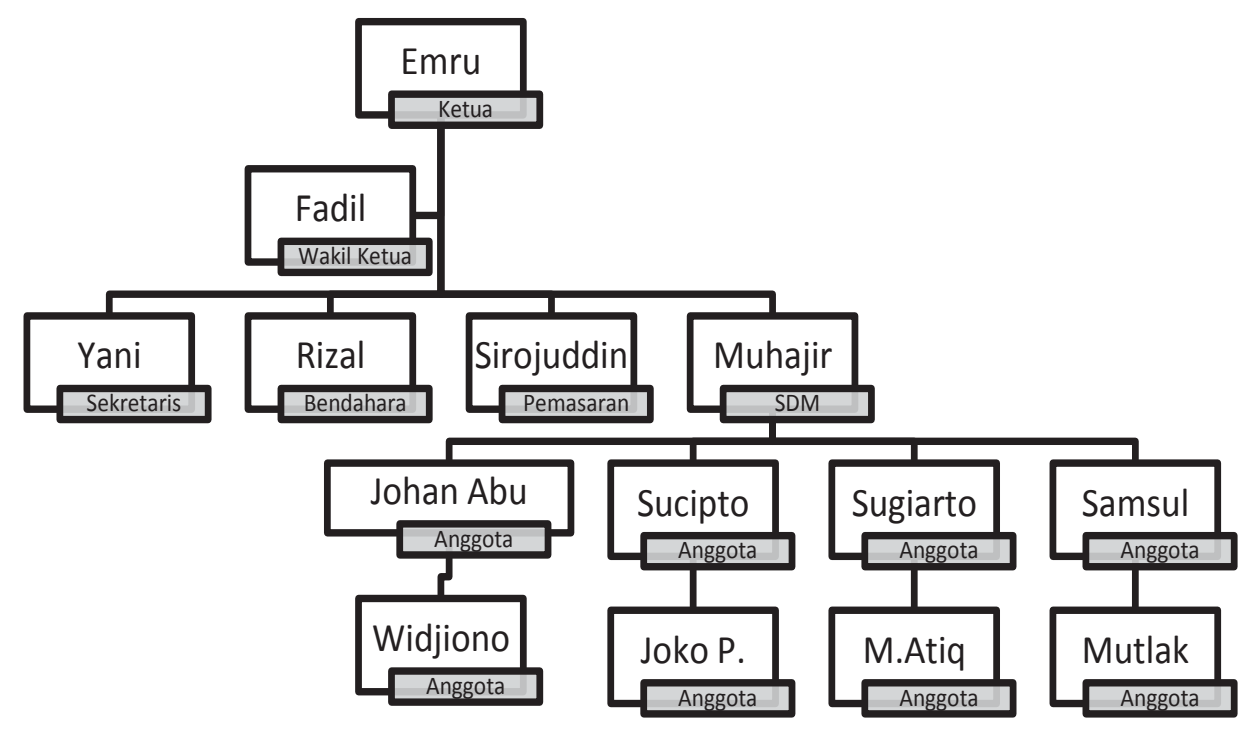

Gambar 1. Struktur Organisasi Pengrajin Kompak 


\begin{tabular}{|c|c|c|c|c|}
\hline Node & Nama Aktor & Atribut & Lambang & Warna \\
\hline 1. & Emru Suhadak & Ketua & Circle & Ungu \\
\hline 2. & Achmad Fadil & Wakil Ketua & Square & Biru Muda \\
\hline 3. & Yani & Sekretaris & Rounded Square & Abu-abu \\
\hline 4. & Rizal & Bendahara & Down Triangle & Hijau \\
\hline 5. & Sirrojuddin & Pemasaran & Plus & Biru Tua \\
\hline 6. & Muhajir & Pengembangan SDM & Box & Putih \\
\hline 7. & Johan Abu & Anggota & Diamond & Hitam \\
\hline 8. & Sugiarto & Anggota & Diamond & Hitam \\
\hline 9. & Samsul & Anggota & Diamond & Hitam \\
\hline 10. & Widjiono & Anggota & Diamond & Hitam \\
\hline 11. & M.Atiq & Anggota & Diamond & Hitam \\
\hline 12. & Mutlak & Anggota & Diamond & Hitam \\
\hline 13. & Joko Purnomo & Anggota & Diamond & Hitam \\
\hline 14. & Sucipto & Anggota & Diamond & Hitam \\
\hline 15. & Anik Nurtiana & Anggota & Diamond & Hitam \\
\hline
\end{tabular}

Tabel 1. Aktor Jaringan Pengrajin di KOMPAK

Berdasarkan tabel di atas maka dapat diketahui posisi aktor berdasarkan tingkat sentralitas aktor dan pengaruhnya terhadap struktur jaringan komunikasi.

\section{b. Analisis Jaringan Komunikasi}

Berdasarkan data struktur organisasi KOMPAK, maka akan dapat dianalisis menggunakan metode analisis jaringan komunikasi untuk melihat sentralitas aktor berdasarkan level sentralitas tingkatan (degree centrality), sentralitas kedekatan (closeness centrality), sentralitas keperantaraan (betweenness centrality), dan sentralitas eigenvektor (eigenvector centrality). Dibawah ini merupakan hasil pengukuran menyeluruh dengan menggunakan software UCINET 6 versi 6.658 .

\begin{tabular}{|c|c|c|c|c|c|c|c|c|c|c|c|c|c|c|c|}
\hline & 1 & 2 & 3 & 34 & $4 \quad 5$ & 6 & 7 & 8 & 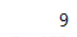 & 10 & 11 & 12 & 13 & \\
\hline & & OutDeg & Indeg & Out2loca & In2local & 1 OutBetaC & InBetaCe & Out2Step & In2Step & OutARD & InARD & OutClose & Inclose & Between & 2StepBet \\
\hline & mru Suhadak & 23.000 & 24.000 & 232.000 & 232.000 & 3778.965 & 3925.770 & 4.000 & 14.000 & & & 14.000 & & & \\
\hline 2 & Achmad Fadil & & & & & 3173.591 & & & & & & & & & \\
\hline & Yani & & & & & 2814.082 & & & & & & & & & \\
\hline & Rizal & & 10 & & & & & & & & & 000 & & & \\
\hline & Sirojuddin & & & & & & & & & & & & & & \\
\hline 6 & Muhajir & & 1 & & & & & & & & & & & & \\
\hline & & & & & & & & & & & & & & & \\
\hline 8 & & & & & & & & & & & & & & & \\
\hline & & & & & & & & & & & & & & & \\
\hline & Widjio & & & & & & & & & & & & & & \\
\hline & & & & & & & & & & & & & & & \\
\hline & & & & & & & & & & & & & & & \\
\hline & ko Purnomo & & & 102.0 & & 1367.921 & & & & & & & & & \\
\hline & Sucipto & & 3.0 & & & & & & & & & & & 0.000 & \\
\hline & ik Nurtiana & 2.000 & 2.000 & 5.000 & & 501.765 & 491.663 & 14.000 & 14.000 & 8.000 & 8.000 & 26.000 & 26.000 & 0.000 & \\
\hline
\end{tabular}

Tabel 2. Pengukuran Menyeluruh (Multiple Measures) Jaringan Pengrajin Kompak

1. Sentralitas Tingkatan ( Degree Centrality)

Tingkatan (degree) memperlihatkan popularitas aktor dalam jaringan sosial. Tingkatan (degree) adalah jumlah link dari dan ke aktor. Dalam jaringan yang directed (mempunyai arah), degree ini bisa berupa indegree (jumlah link atau ties yang mengarah ke aktor) dan outdegree (jumlah link yang keluar dari aktor) (Eriyanto, 2014).

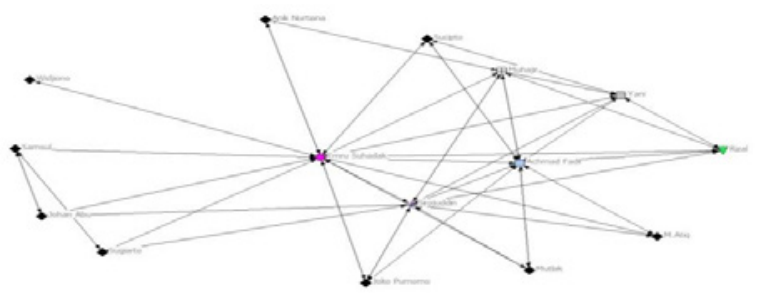

Gambar 2. Jaringan Pengrajin Kompak 
Pada jaringan komunikasi antara pengrajin sepatu yang tergabung dalam Komite Pengusaha Alas Kaki Kota Mojokerto (KOMPAK) dapat diketahui total dari indegree dan outdegree sebanyak 15 links. Angka tingkat sentralitas tingkatan diukur berdasarkan skala 0 sampai dengan 1 . Aktor yang memiliki sentralitas tingkatan tertinggi adalah node 1 yaitu pak Emru. Outdegree Emru adalah 0,548 dengan jumlah link sebanyak 23. Indegree terbanyak juga terdapat pada Emru sebanyak 0,571 dengan 24 ties. Data ini memperlihatkan bahwa Emru adalah aktor paling populer dalam jaringan karena jabatan di organisasi adalah sebagai ketua. Emru adalah seseorang yang sering berinteraksi dengan anggota dan menjalin kontak dengan aktor-aktor yang ada dalam jaringan. Sementara aktor dengan popularitas terendah dengan outdegree 0,024 adalah node 10 yaitu pak Widjiono.

\section{Sentralitas Kedekatan (Closeness Centrality)}

Analisis pada tabel 2 menjelaskan bahwa sentralitas kedekatan menggambarkan seberapa dekat aktor (node) dengan semua aktor lain di dalam jaringan. Kedekatan diukur dengan dari berapa langkah (jalur/path) seorang aktor bisa menghubungi atau dihubungi oleh aktor lain dalam jaringan (Eriyanto, 2014). Semakin rendah nilai kedekatan, akan semakin baik karena memperlihatkan jarak yang rendah setiap aktor untuk berhubungan dengan aktor lain. Aktor yang memiliki tingkat kedekatan rendah adalah node 1 yaitu Emru. Emru hanya membutuhkan 1 langkah untuk menghubungi aktor lain. Sementara aktor dengan kedekatan terburuk adalah Widjiono dengan nilai 0,519 karena aktor ini memang jarang berkumpul dan bertatap muka dengan aktor-aktor lain dalam jaringan. Node 1 dinilai memiliki kedekatan dengan para pengrajin alas kaki lainnya mengingat peran node 1 adalah sebagai ketua yang memimpin organisasi KOMPAK.

\section{Sentralitas Keperantaraan (Betweenness Centrality)}

Sentralitas Keperantaraan memperlihatkan posisi seorang aktor sebagai perantara (betweenness) dari hubungan aktor satu dengan aktor lain dalam suatu jaringan. Sentralitas keperantaraan dianggap penting karena berkaitan dengan kontrol dan manipulasi informasi (Eriyanto, 2014). Semakin tinggi nilai keperantaraan, maka semakin penting posisi seorang aktor karena menunjukkan aktor satu harus melewati aktor tersebut agar bisa berhubungan dengan aktor lain. Dari data yang telah disajikan, aktor Emru menempati posisi sebagai aktor dengan derajat keperantaraan tertinggi, yaitu sebanyak 97,167. Sedangkan untuk posisi aktor dengan derajat keperantaraan terendah, yaitu Widjiono, Atiq, Mutlak, Joko Purnomo, dan Anik Nurtiana. Aktor-aktor ini tidak berperan sebagai penghubung yang menghubungkan aktor satu dengan aktor lainnya. Node 10, node 11, node 12, node 13 memang memiliki tingkat keperantaraan yang rendah karena kurangnya komunikasi atau jarang berkumpulnya mereka di organisasi KOMPAK.

\section{Sentralitas Eigenvektor (Eigenvector Centrality)}

Sentralitas Eigenvektor bisa melihat seberapa penting orang yang mempunyai jaringan dengan aktor. Seberapa penting ini digambarkan sebagai seberapa banyak jaringan yang dipunyai oleh orang/organisasi/institusi yang mempunyai relasi dengan aktor atau dengan kata lain seberapa populer node yang berjaringan dengan aktor (Eriyanto, 2014). Aktor yang memiliki nilai eigenvektor tertinggi adalah Emru dengan nilai 0,471, Node 1 tetap dinilai menjadi aktor penghubung antar pengrajin dan pemerintag daerah. Node 1 memiliki tingkat kepopuleran diantara pengrajin alas kaki Kota Mojokerto sebagai pusat dari informasi terkait dengan usaha, sedangkan aktor dengan nilai eigenvektor terendah adalah Widjiono dengan nilai 0,035. Nilai eigenvektor tertinggi menunjukkan bahwa aktor tersebut memiliki peran penting dalam jaringannya.

\begin{tabular}{|c|c|c|c|}
\hline \multicolumn{4}{|c|}{ Level Aktor Sentralitas } \\
\hline Sentralitas Tingkatan & Sentralitas Kedekatan & Sentralitas Keperantaraan & Sentralitas Eigenvektor \\
\hline Emru & Emru & Emru & Emru \\
\hline
\end{tabular}

Tabel 2. Level Aktor Sentralitas

Dari hasil analisis level aktor berdasarkan sentralitas, diketahui bahwa aktor Emru menguasai sentralitas dalam jaringan yang ada di organisasi KOMPAK. Aktor Emru menempati empat posisi sentralitas (tingkatan, kedekatan, keperantaraan, dan eigenvektor). Melihat peran posisi jabatan ketua di organisasi KOMPAK membuat aktor Emru harus memiliki kedekatan dan menjadi penghubung antar anggota aktor di jaringan komunikasi kompak tersebut. Aktor Emru juga dinilai dapat menjalin relasi atau hubungan yang baik dengan aktor-aktor lain sebagai pemimpin dalam organisasi yang diketuainya. Node 1 yaitu pak Emru Suhadak memang menguasai keempat sentralitas di atas, aktor ini dikenal sebagai aktor utama yang memiliki peran dominan untuk mewakili aspirasi para pengrajin dan sebagai jembatan pemerintah daerah (Disperindag Kota Mojokerto) dalam menyalurkan program-program terkait dengan perindustrian dan perdagangan alas kaki. 


\section{KESIMPULAN}

Jaringan komunikasi yang terbentuk dalam Komite Pengusaha Alas Kaki Kota Mojokerto terkait dengan proses pertukaran informasi yaitu bersifat memusat (interlock personal network). Hal ini dikarenakan adanya peran yang dominan salah satu individu dalam jaringan komunikasi tersebut. Individu Emru merupakan individu yang berperan sebagai pusat penyaluran informasi dalam organisasi tersebut. Individu Emru merupakan ketua dari KOMPAK yang memiliki jaringan kedekatan antar pengrajin alas kaki di Kota Mojokerto dan juga mempunyai hubungan kedekatan kepada pemerintah daerah (Disperindag). Individu ini memiliki kemampuan lebih dalam berkomunikasi, sehingga terlihat jelas bahwa sentralitas pada level aktor berpusat kepada ketua dari KOMPAK sendiri.

\section{DAFTAR PUSTAKA}

Acock, A. C., \& Hurlbert, J. S. (1990). Journal of Social and Personal. https://doi.org/10.1177/0265407590072006.

Antoniadis, I., \& Charmantzi, A. (2016). Social network analysis and social capital in marketing: theory and practical implementation. International Journal of Technology Marketing, 11(3), 344-359.

Ardhala, A. D., Eko, I., Santoso, B., Ir, I., \& Sulistiyarso, H. (2016). Determining The Potential Footwear Village To Developed As Creative Industries Tourism Area Study Case : Footwear Village, Mojokerto City, Indonesia, 536-542. https://doi.org/10.15680/IJIRSET.2015.0501087.

Badi, S., Wang, L., \& Pryke, S. (2017). Relationship marketing in Guanxi networks: A social network analysis study of Chinese construction small and medium-sized enterprises. Industrial Marketing Management, 60, $204-218$. https://doi.org/10.1016/j.indmarman.2016.03.014.

Bashor \& Purnama (2017). Factors Affecting Performance Manager and Its Impact on Competitive Advantage : Studies Small Medium Enterprises ( SMEs ) in The Shoes Industry Mojokerto East Java Province Choirul Bashor Chamdan Purnama, 8(4), 153-162. https://doi.org/10.1515/mjss-2017-0014.

Borgatti, S. P., \& Foster, P. C. (2003). The network paradigm in organizational research: A review and typology. Journal of Management, 29(6), 991-1013. https://doi.org/10.1016/S0149-2063(03)00087-4.

Creswell, J.C. (2012). Education Research, Planning, Conducting and Evaluating Quantitative and Qualitative Research. 4th edition. Boston: Pearson.

Crossley, N., Prell, C., \& Scott, J. (2009). Social Network Analysis : Introduction to Special Edition, 4, 1-5.

Galaskiewicz, J., \& Wasserman, S. (1993). Sociological Methods \&. https://doi.org/10.1177/0049124193022001001

Guo, L. (2012). The Application of Social Network Analysis in Agenda Setting Research: A Methodological Exploration. Journal of Broadcasting and Electronic Media, 56(4), 616-631. https://doi.org/10.1080/08838151.2012.732148.

Hertanto, D., \& Safitri, R. (2016). Analisis Struktur Jaringan Komunikasi dan Peran Aktor Dalam Penerapan Teknologi Budidaya Kentang ( Petani Kentang Desa Ngantru Kecamatan Ngantang Kabupaten Malang ) Structure Analysis of Communication Network and The Role Players Technology Application in Raising The Potato ( A Potato Farmer village Ngantru, Ngantang Malang ), 27(2), 55-65. https://doi.org/10.21776/ub.habitat.2016.027.2.7.

Huisman, M dan Duijn M.A.( 2005). A Readeres Guide to SNA Software dalam Scott, John dan Carrington, J.P (ed). 2011. The SAGE Handbook of Social Network Analysis. Singapore. SAGE.

Latuperissa, R. (2014). Network Mapping of SME's in Borobudur Cluster Using Social Network Analysis for Strengthening Local Economic Development Platform, 11(3), 161-167.

Ioanid, A., Deselnicu, D. C., \& Militaru, G. (2018). The impact of social networks on SMEs' innovation potential. Procedia Manufacturing, 22, 936-941. https://doi.org/10.1016/j.promfg.2018.03.133.

Molano, S., \& Polo, A. (2015). Social Network Analysis in a Learning Community. Procedia - Social and Behavioral Sciences, 185(57), 339-345. https://doi.org/10.1016/j.sbspro.2015.03.381.

Monaghan, S., Lavelle, J., \& Gunnigle, P. (2017). Mapping networks: Exploring the utility of social network analysis in management research and practice. Journal of Business Research, 76, 136-144. https://doi.org/10.1016/j. jbusres.2017.03.020.

Otte, E., \& Rousseau, R. (2002). Social network analysis : a powerful strategy, also for the information. https://doi. org/10.1177/016555150202800601.

Phillips, D. M., Keith, J., Phillips, D. M., \& Phillips, J. K. (2006). transportation. 
Pinho, J. C., \& Pinheiro, M. L. (2015). Social network analysis and the internationalization of SMEs: Towards a different methodological approach. European Business Review, 27(6), 554-572. https://doi.org/10.1108/EBR-10-20140075 .

Rauch, J. E. (2001). Business and Social Networks in International Trade. Journal of Economic Literature, 39(4), 11771203. https://doi.org/10.1257/jel.39.4.1177.

Scott, J. (1988). http://soc.sagepub.com/ Social Network Analysis. https://doi.org/10.1177/0038038588022001007

Smångs, M. (2006). The nature of the business group: A social network perspective. Organization, 13(6), 889-909. https://doi.org/10.1177/1350508406068816.

Sozen, C., \& Hazir, K. (2009). Social Network Analysis in Organizational Studies. International Journal of Business and Management, 1(1), 1309-8047. Retrieved from http://www.sobiad.org/ejournals/journal_IJBM/arhieves/ ijbm2009/03CenkSozen.pdf.

Williams, T. A., \& Shepherd, D. A. (2017). Mixed Method Social Network Analysis: Combining Inductive Concept Development, Content Analysis, and Secondary Data for Quantitative Analysis. Organizational Research Methods, 20(2), 268-298. https://doi.org/10.1177/1094428115610807.

Zulkarnain, Lubis, D. P., Satria, A., \& Hubeis, M. (2015). Jaringan Komunikasi Dalam Kegiatan Produksi Dan Pemasaran Pada Pembudidaya Ikan. Jurnal Sosial Ekonomi Kelautan Dan Perikanan, 10(1), 115-124. Retrieved from http:// ejournal-balitbang.kkp.go.id/index.php/sosek/article/download/1252/1146. 